\title{
A DESIGN CASE STUDY: 3D PRINTER SOFTWARE INTERFACE DESIGN BASED ON HOME USERS PREFERENCES KNOWLEDGE
}

\author{
Li, Xuenan; Zhao, Danhua; Zhao, Jianghong \\ School of Design, Hunan University
}

\begin{abstract}
The rapid development of 3D printing technology has an impact on all aspects of modern manufacturing, design and society. However, the home use of $3 \mathrm{D}$ printers is still limited by the difficulty in deploying the software and the technology which both need professional understanding and training. How to enable non-technical home users to use 3D printers without the need for training, becomes an urgent problem for both academics and the industry. This paper is concerned in an investigation into home use of 3D printers, their needs and preferences, their impacts on the interaction design of 3D printing. First, a questionnaire survey supported by 127 non-technical users is conducted to understand their preferences on several key steps of the 3D printing procedure. Then, we integrate the survey results into the interaction design process to improve the usability of the 3D printing software. Finally, the advantage of our implementation is tested via the user satisfaction and feedback towards the post-use period. Our design project shows a simple method to extend 3D printing interactive software to non-technical users, and pushes forward the landscape of the home use of 3D printers.
\end{abstract}

Keywords: Design methods, 3D printing, User centred design, Human-Machine Interfaces, User preference

Contact:

Li, Xuenan

Hunan University, China

School of Design

China, People's Republic of

xuenan332@sina.com

Cite this article: Li, X., Zhao, D., Zhao, J. (2019) 'A Design Case Study: 3D Printer Software Interface Design Based on Home Users Preferences Knowledge', in Proceedings of the 22nd International Conference on Engineering Design (ICED19), Delft, The Netherlands, 5-8 August 2019. DOI:10.1017/dsi.2019.68 


\section{INTRODUCTION}

3D Printing technology originated in the United States at the end of the 19th century and was originally used in the industrial area. It was not until the 1980s that it began to develop and promote. In 1984, Chuck Hull 3D Systems applied for a patent for Stereo Lithography Apparatus technology (Micallef J, 2005). Early 3D Printers did not print well and were expensive, only a few models workshops, academic institutes and factories can afford to use 3D Printing technology (Gershenfeld N, 2008). In recent years, along with the improvement in the quality and technology popularization, the reduction in the price of 3D Printers based on FDM (Fused Deposition Modelling) has led to the development of the 3D Printing market (Turbovich Z N, 2017). The main reason is the expiration of the FDM technology patent protection in 2009 (Mueller S, 2017).

In terms of user needs, consumers tend to play a more and more important role in developing designs for production and act as the designers of the product he/she wants to use (Von Hippel E, 2012). Traditionally, professional designers are responsible for designing products for consumers. However, many companies also develop products that are not designed by professional designers, but design by the consumers themselves (Von Hippel E, 2005). In response to the growing personal needs of consumers, companies are paying attention to mass customization (Huang X, 2008). The combination of computer, Internet and 3D Printing technologies caters to the needs of mass customization, presenting opportunities for a new paradigm of product creation (Hu S J, 2013). However, the promotion of 3D Printing technology is severely limited by the education needed to use the devices (Neagle C, 2013). Easton (2009) says that " As things stand today, home 3D Printers are at about the same level of capability, user-friendliness as personal computers in the mid-1970s".

According to the survey in (Shapeways, 2012), ease of use is also one of the most wanted features in 3D Printing technology. However, there is very little work to improve the usability for home users. Specifically, there is a need for home users to use its software and hardware without systematic training. A survey supported by 42 university students in (Underwood G, 2014) finds that skill levels made a difference when 3D Printing, and interestingly led to divergent design trajectories. Students with lower skill levels prefer keeping design works simple. Home users are non-technical and those with lower skill levels, designers should not ignore their needs in the usability of software cooperation hardware.

This study is concentrated on home users and aims to make non-technical home users use 3D Printers without the need for training or the ability to program. In this paper, we investigate the needs and preferences of non-technical home users and integrate them into the 3D Printing interactive software design process. The ContinUE (Continuous User Experience) model (Pohlmeyer A E, 2009) is implemented in this study as a systematic guide on our design process.

This study is built on the design project of a desktop-level 3D Printer based on FDM technology to improve the home user experience of 3D Printer. The contribution of this design project is a simple and convenient method to extend 3D Printer interactive software cooperation hardware from professional users to non-technical users.

\section{METHODOLOGY}

\subsection{Users and the design process}

Users are a considerable part of the design process. A large number of design-related research efforts are focused on improving the user experience (Chamorro-Koc M, 2008), incorporating users into the design process (Sanders E B N, 2012) or meeting user needs (Boztepe S, 2007). Cross (2011) says that "Designing is an iterative process that involves "moving-seeing-moving", where moving is defined as the problem and seeing is defined as the solution. Thus, the designers of the interface aiming at doing the printing successfully are believed to constantly solve design problems using knowledge from different sources (Groat L N, 2013). Users are one of the sources of knowledge. For 3D Printing, there is a variety of information about non-technical home users, but not all of this information can become knowledge. Blackmer (2005) distinguished between information and knowledge, where information could be considered knowledge without purpose. User information like name, age, gender, preferences cannot be used as knowledge until they are proven to be significantly relevant to the design purpose. 
For designers, how to get user representations related to design purposes is a key issue in designing with user information.

\subsection{Design process based on continuous user experience model}

There are many design processes actively used to improve the user experience. The design innovation (DI) process (Camburn B A, 2017) shows four design phases associated with user representations: (1) User study, including the market assessment and need determination; (2) User modelling, including the market modelling and requirement specification; (3) Information organization, including the system layout and architecture; (4) Product prototyping, including the cost-benefit analysis and market penetration.

The ContinUE model is a complete life cycle of user experience, where the user experience is dismantled into five phases: (1) Anticipated Experience; (2) Use Experience; (3) Reflective Experience; (4) Repetitive Experience; (5) Retrospective Experience.

This model is implemented in the case study of 3D Printer software interface design and mapped to the DI process. This modified model (Figure 1) illustrates the evolution of the user experience along seven detailed phases:

1. Pre-design: investigating the user preferences and needs using survey questionnaires, Face-toFace Interviews, Focus Group, etc. This phase is mapped to the user study and user modelling phases in the DI process.

2. Design: forming flowcharts and user interfaces by integrating the user experience with the user needs. This phase is mapped to the information organization phase in the DI process.

3. Test: providing public or non-public user testing of the product. This part can be implemented as multiple or step-by-step testing.

4. Evaluate: Optimizing the product to prepare for the Release section based on the testing data (Including the feedback of the user's operation behavior and the psychological feeling).

5. Release: releasing different product versions.

6. Feedback: Proving the user feedback through product feedback portal after a product launched officially. The phases from 3 to 6 are all mapped to the product after the prototyping in the DI process.

7. Update: Repeating the above steps from 2 to 6 to complete the life cycle of the user experience.

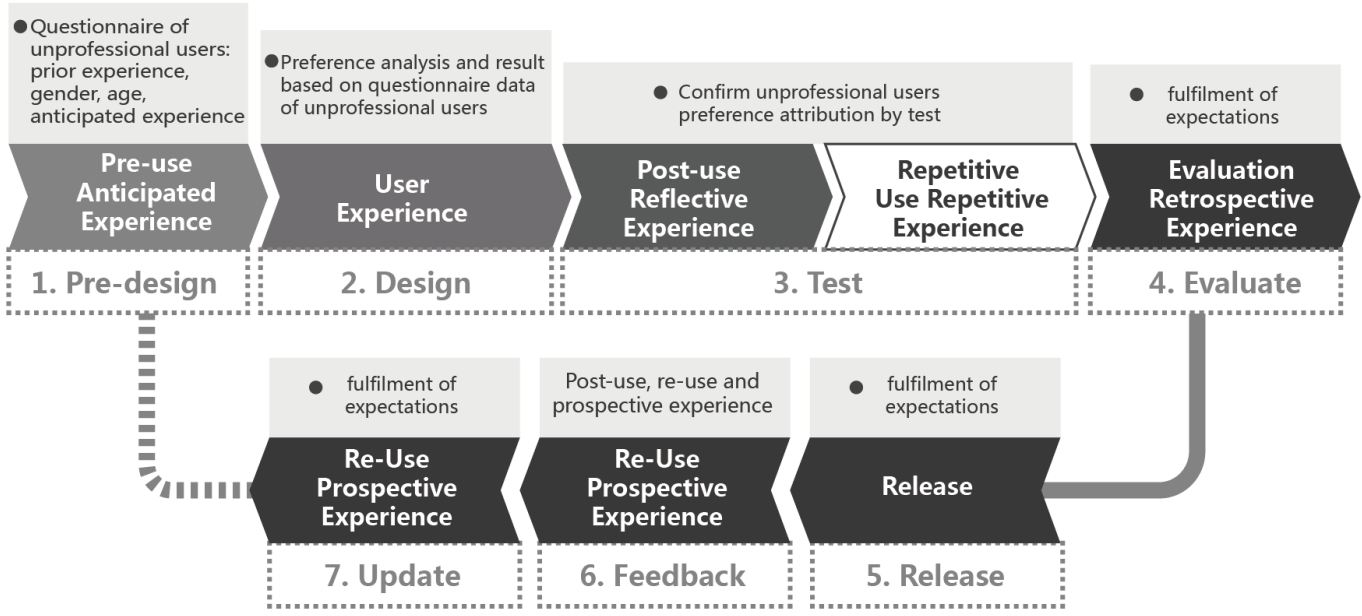

Figure 1. Design process based on continuous user experience model

\section{A DESIGN CASE STUDY: 3D PRINTING SOFTWARE INTERFACE DESIGN}

\subsection{The key steps in a basic 3D printing flow}

The stages in 3D Printing workflows that impact the user experience can be shown in Figure 2: Plan, Create/ Download a 3D model, Setup, Verify, and Print (Hudson N, 2016). Home users often struggle in "Create/ Download a 3D model" and "Setup" stages, which seriously affect their final printed output. There are two key difficulties for users in these stages: (1) Home users have little or no prior 3D modelling experience and tend to download a free and premade 3D model from a website. 
However, these premade models probably don't match with users' original intent. Thus, there is a lack of personalized customization channel aims to home users. (2) Home users lack professional knowledge to use 3D printers, inappropriate parameter settings and 3D models can cause printing to fail. Therefore, it is necessary for home users to make a quick understanding of their preferences and requirements in the "Create/ Download a 3D model" and "Setup" steps, to improve the user experience of the 3D printing software.

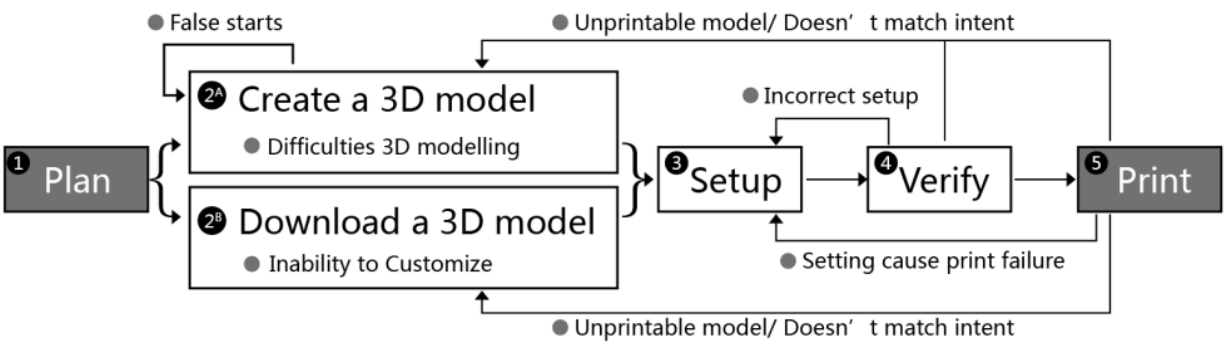

Figure 2. 3D printing basic flow

\subsection{Pre-design: questionnaire of home user's preference in 3D printing key steps}

To create a precise picture of the home user's preference, we use a survey questionnaire as Table 1 to collect data. For the "Creating/ Download a 3D model" step, home users have three options: (1) Design 3D models by home users themselves; (2) Find professionals to design 3D models; (3) Download premade 3D models.

For "Setup" part, home users also have three choices: (1) The parameters are all set by the software automatically; (2) Parameters are partly set by home users themselves; (3) The parameters are all set by home users themselves. The data collection process took more than 3 months, feedback from 127 home users is collected based on their preferences. Among the users surveyed, 56 are males and 71 are females, of which $82 \%$ have heard or seen more 3D Printers, and $18 \%$ have never seen or heard of them. Only $8 \%$ of respondents have operated 3D Printers. The age span is 18-55 years old and the average is 31.7 years old. All the basic information of home users surveyed can be seen in Figure 3 .

Table 1. Questionnaire of home user preferences in 3D printing

\begin{tabular}{|c|c|c|}
\hline No. & Question & Option \\
\hline \multirow[t]{3}{*}{1} & \multirow{3}{*}{$\begin{array}{l}\text { If you have a 3D printer } \\
\text { which can match your } \\
\text { needs mostly, then you } \\
\text { will: }\end{array}$} & A. Design a 3D model and Printing by myself \\
\hline & & B. Find someone to customize 3D model, then printing by myself \\
\hline & & $\begin{array}{r}\text { C. Choose3D model which is already finished, then printing by } \\
\text { myself }\end{array}$ \\
\hline \multirow[t]{3}{*}{2} & \multirow{3}{*}{$\begin{array}{c}\text { If you have a 3D printer } \\
\text { which can match your } \\
\text { needs mostly, then you } \\
\text { prefer: }\end{array}$} & $\begin{array}{r}\text { A. print parameters are matched and chosen based on the chosen 3D } \\
\text { model situation by software automatically }\end{array}$ \\
\hline & & $\begin{array}{r}\text { B. print parameters are partly chosen by system, and choosing left } \\
\text { parameters by myself }\end{array}$ \\
\hline & & C. choosing all print parameters by myself \\
\hline
\end{tabular}

In order to analyse user preferences based on questionnaire results, we concatenate the user responses to the questionnaire into a six-dimensional vector. The meaning of each dimension is as follows:

- Whether to download premade 3D models, 1 is Yes and 0 is No.

- Whether to find professionals to design 3D models, 1 is Yes, 0 is No.

- Whether to design 3D models by home users themselves, 1 is Yes, 0 is No.

- Whether to set 3D Printing parameters by software automatically, 1 is Yes, 0 is No.

- Whether to set all 3D Printing parameters by home users themselves, 1 is Yes, 0 is No.

- Whether to set partial 3D Printing parameters by home users themselves, 1 is Yes, 0 is No.

For example, the result can be shown as $p_{k}=[0,0,1,0,1,0]$, when the $\mathrm{k}$-th user chooses to design the 3D model by himself or herself, and set all 3D Printing parameters by himself or herself. It is worth noting that in the first three options of the questionnaire, the user can only select one item, which means that each user can only select one preferred operation when creating/download 3D models. Similarly, in the last three choices, the user can only select one. 

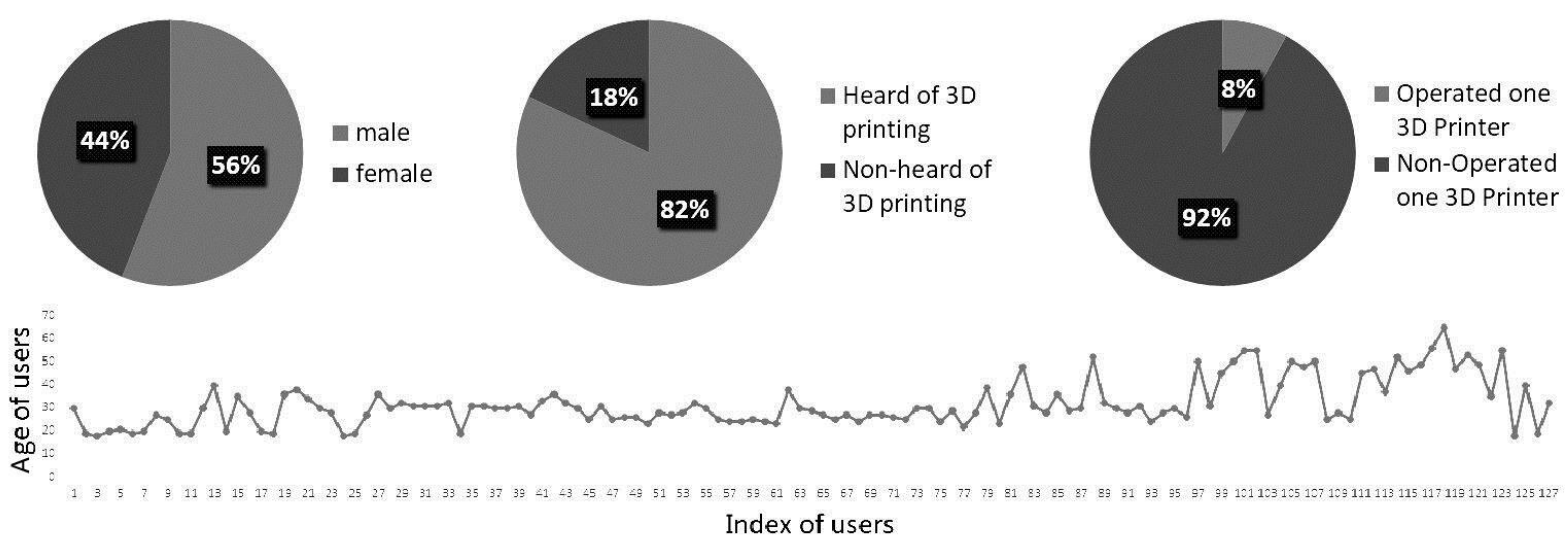

Figure 3. The basic information of home users surveyed

Based on the cluster analysis of questionnaire results (4 clusters), the information that home users prioritized in relation to the design purpose can be concluded as follows:

- The three options in the "Creating/ Download 3D models" step are all reasonable choices for home users. Among them, the third option accounts for about 50\%, meaning that nearly half of the home users tend to design 3D models by themselves.

- Only the first and third options in the "Setup" step are reasonable choices for home users. Among them, the first option accounts for about $70 \%$, meaning that nearly $70 \%$ of the users choose to set 3D printing parameters by the software automatically, 30\% of the home users choose to set partial 3D printing parameters by themselves, no one likes choosing to set all 3D printing parameters by themselves.

- The four clusters in the table have their specific combination of preferred operations. For example, as shown in cluster $\mathrm{C}$ and $\mathrm{D}$, when the users want to find professionals to design $3 \mathrm{D}$ models or download premade 3D models, they must also hope to set 3D Printing parameters by the software automatically.

Among the three options in the "Creating/ Download 3D models" step, the number of home users tends to be equally distributed. Therefore, this step should be subdivided into three types and in a sideby-side relationship in the design process. However, for the three options in the "Setup" step, the number of home users is clearly non-uniformly distributed. Among them, no one user chooses to configure all 3D Printing parameter by themselves. Therefore, the designers who help to do the printing successfully by designing interface should avoid providing all the parameters configuration options to home users after the model is loaded. To meet the needs of $30 \%$ users to set partial parameters by themselves, the designers can appropriately highlight the simple parameter configuration options, automatically configure most difficult parameters, and weaken or hide these high-level interactions in the user interaction process.

Table 2. Home user preference cluster result in the key step

\begin{tabular}{|c|c|c|c|c|}
\hline \multirow[t]{2}{*}{ Type } & \multirow{2}{*}{$\begin{array}{l}\text { Cluster } \\
\text { centre }\end{array}$} & \multicolumn{2}{|r|}{ Home User Preference in Key Steps } & User \\
\hline & & Model Source & Parameter Configuration & Quantity \\
\hline A & {$[0,0,1,1,0,0]$} & $\begin{array}{r}\text { Design 3D model } \\
\text { by myself }\end{array}$ & $\begin{array}{r}\text { print parameters are matched and chosen based } \\
\text { on the chosen 3D model situation by software } \\
\text { automatically }\end{array}$ & 30 \\
\hline B & {$[0,0,1,0,0,1]$} & $\begin{array}{r}\text { Design 3D model } \\
\text { by myself } \\
\end{array}$ & $\begin{array}{r}\text { print parameters are partly chosen by system, and } \\
\text { choosing other parameters by myself }\end{array}$ & 37 \\
\hline $\mathrm{C}$ & {$[0,1,0,1,0,0]$} & $\begin{array}{r}\text { Find someone to } \\
\text { customize 3D } \\
\text { model } \\
\end{array}$ & $\begin{array}{r}\text { print parameters are matched and chosen based } \\
\text { on the chosen 3D model situation by software } \\
\text { automatically }\end{array}$ & 30 \\
\hline $\mathrm{D}$ & {$[1,0,0,1,0,0]$} & $\begin{array}{r}\text { Choose } 3 \mathrm{D} \\
\text { model which is } \\
\text { already finished }\end{array}$ & $\begin{array}{r}\text { print parameters are matched and chosen based } \\
\text { on the chosen 3D model situation by software } \\
\text { automatically }\end{array}$ & 30 \\
\hline
\end{tabular}


The correlation coefficient is often used to study the linear correlation between variables. In this paper, the Pearson correlation coefficient is used to analyze the influence of the user's basic information on the user's operation preference. The correlation value ranges from 0 to 1 . The closer the value is to 0 , the less relevant the two variables are. The closer the value is to 1 , the two variables are more correlated.

Correlation coefficients between user basic information in Figure 3 and the user's preference clustering results in Table 2 can be seen as follows:

- The correlation coefficient between user gender and clustering results is 0.01 .

- The correlation coefficient between user age and clustering results is 0.02 .

- The correlation coefficient between "whether the user has heard of 3DPrinting" and clustering results is 0.06 .

- The correlation coefficient between "whether the user has operated one 3D printer" and clustering results is 0.06 .

The correlation coefficient results show that the home user's gender, age, and 3D Printing experience have less impact on their operational preferences. From the distribution in Table 3, there is no obvious tendency for users who have heard of 3D Printing or have operated 3D Printers in the four clusters. Therefore, home user's gender, age and 3D Printing experience are almost irrelevant to design purposes, this information cannot be used as knowledge to guide the design process.

Table 3. Correlation analysis of home user information

\begin{tabular}{|c|c|c|c|c|c|}
\hline \multirow[t]{2}{*}{ Type } & \multirow{2}{*}{$\begin{array}{l}\text { Cluster } \\
\text { centre }\end{array}$} & \multicolumn{4}{|r|}{ Home users number } \\
\hline & & $\begin{array}{r}\text { Heard of 3D } \\
\text { Printing }\end{array}$ & $\begin{array}{r}\text { Non-heard of 3D } \\
\text { Printing }\end{array}$ & $\begin{array}{r}\text { Operated one 3D } \\
\text { Printer }\end{array}$ & $\begin{array}{r}\text { Non-operated one } \\
\text { 3D Printer }\end{array}$ \\
\hline A & {$[0,0,1,1,0,0]$} & 25 & 5 & 2 & 28 \\
\hline B & {$[0,0,1,0,0,1]$} & 29 & 8 & 4 & 33 \\
\hline $\mathrm{C}$ & {$[0,1,0,1,0,0]$} & 25 & 5 & 2 & 28 \\
\hline D & {$[1,0,0,1,0,0]$} & 25 & 5 & 2 & 28 \\
\hline
\end{tabular}

\subsection{D printing software user interface design, testing and evaluation}

User knowledge related to design purposes is stored as their preferences in the questionnaire results in Section3.2. In this section, the preferences of non-technical home users are applied to the 3D Printing interactive software design process. As shown in Figure 4, the "Create/ Download a 3D model" and "Setup" steps are redesigned to meet user needs. There are four types of model sources for users to create or download a 3D model file, which are all essential for home users according to Table 2:

- Local-storage: Free models that come with 3D Printing software, these models are specially designed and optimized for 3D Printing.

- Model Library Cloud: Premade 3D models stored on cloud servers. These models are shared by professional or non-professional designers, some of which require paid downloads.

- External storage: Import 3D models into 3D Printing software via an external mobile storage device.

- Hand-painted 3D Graphics: An APP in 3D Printing software, which generates plane sketches, and then automatically generates 3D models based on sketches.

In the "Setup" step, the software automatically enables the default parameters, since nearly $70 \%$ of home users tend to use the default parameters. We also design partial custom parameters to meet the other $30 \%$ of users, for example, modifying the print density, using the support base or not, and so on. Real-time browsing information is categorized at different steps for home users to check printingrelevant status information in each session. Before confirming the print, home users can view the slicing result, the duration evaluation and the printing preview at any time to confirm whether it can be printed. After that, home users can browse the remaining printing time, the G-Code process, real-time nozzle coordinate position and other information. During the printing process, home users can abort or pause printing at any time. After printing finished, the printing interface can automatically return to the main interface. At last, the output is that a 3D model is printed successfully. 


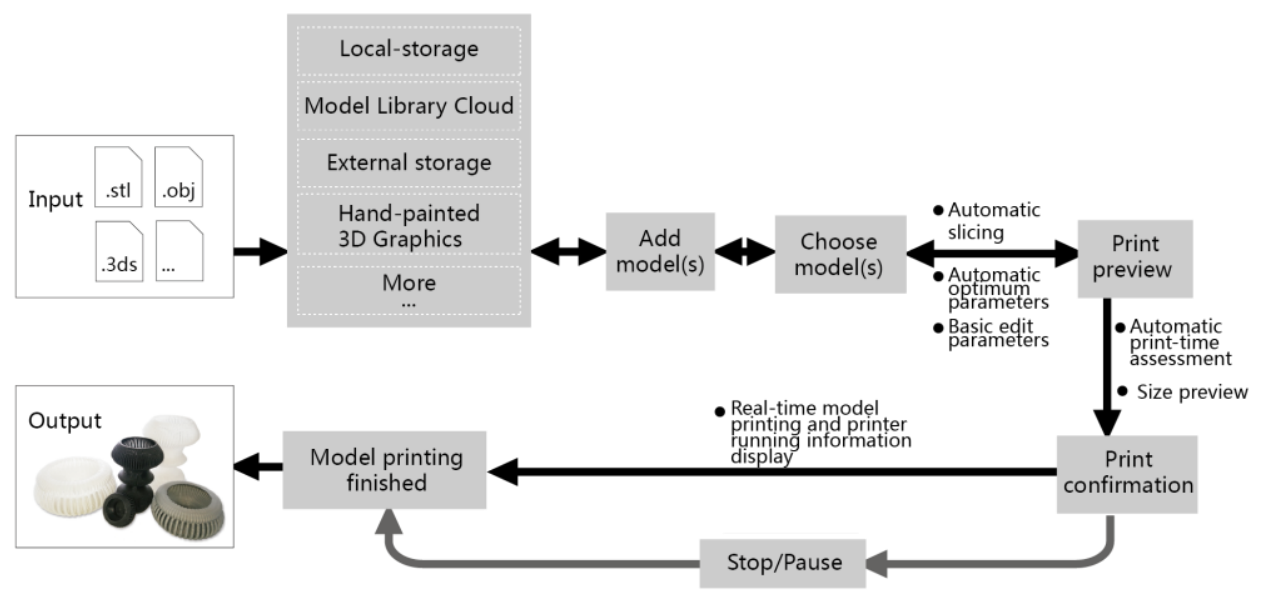

Figure 4. 3D printing flow design

Based on Figure 4, we designed the user interface called Neobox- 3D Printing Software. The interface size of the touch screen is 8 inches, and the colour is dark blue with a scientific sense. In each interface, only the current operational tasks are highlighted, which helps users to concentrate on operations and reduce the distributed elements, as shown in Figure 5. Interface 1 is the first page of "Add models", users can see the above four model selection entries on this page. Interface 2 is for users to browse existing models or create their own models. Users select the model in interface 3, and then edit the model in interface 4 , where they can adjust the size, position, and orientation of the model by dragging and dropping the model. This page retains the advanced parameter settings entry for users to make advanced parameter settings. After clicking "Print", the interface 5 will pop up, the model will automatically enable the default settings. Home users can make some custom settings on this page as well. Interface 6 shows the slicing process of the model. Interface 7 is a preview result after the model is sliced. Interface 8 displays real-time information such as nozzle heating temperature and progress. Interface 9 shows information related to the progress of the printing, for example, the number of print layers, the coordinates of the print head, and the like. Interface 10 shows that printing is complete. After clicking "Ok", users can take out the printed model from the machine. Following the design process model in Figure 1, the user feedback through the feedback portal of the product is collected to see if there is any significant effect for home users to use 3D printers without the need for training.

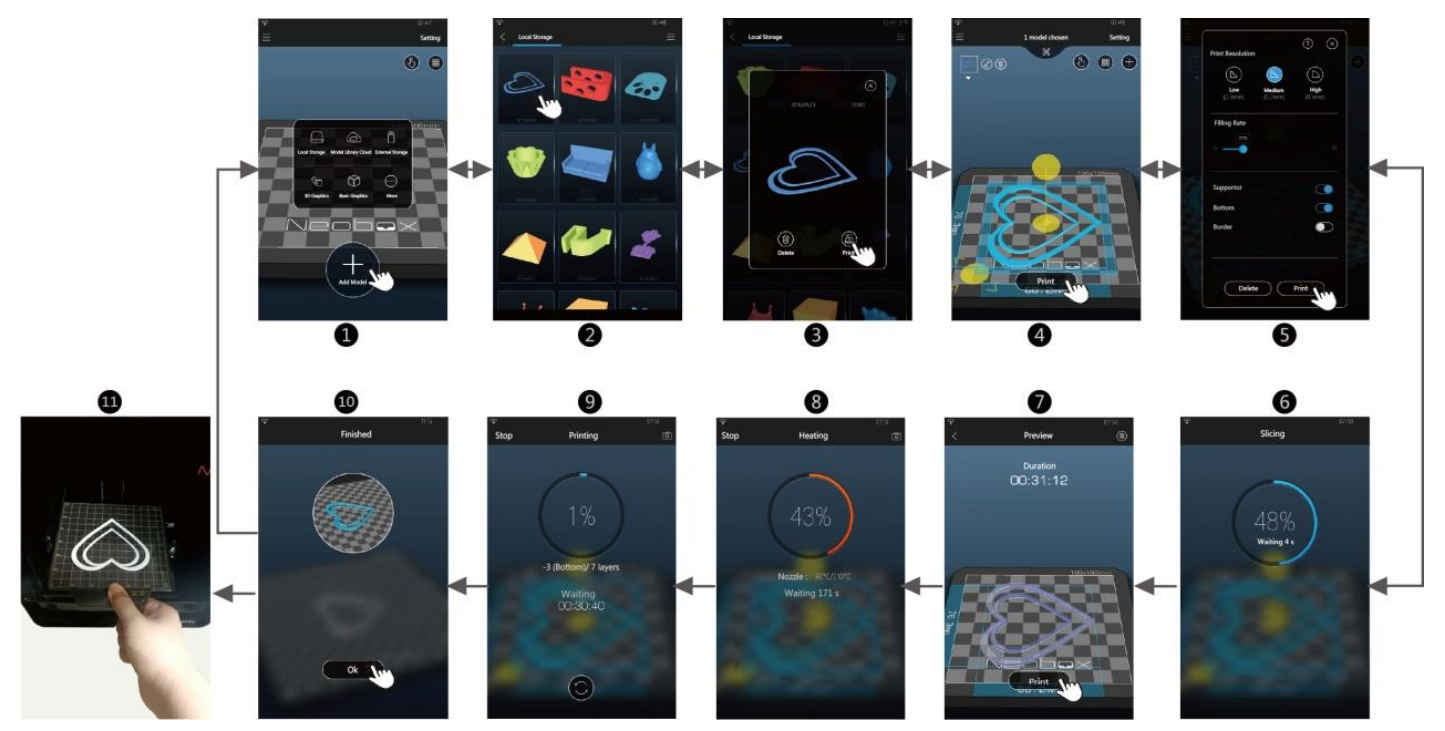

Figure 5. The screenshot of 3D printing software user interface

In the testing phase, two pieces of equipment are used as follows:

- $\quad 8$-inch tablet PC equipped with Neobox-3D Printing software. Neobox software is compatible with 40 model file formats such as STL, OBJ, OFF, 3DS, etc. Pre-defined or downloaded models are simple 3D models without having print parameters. When the model file is loaded to the printing platform, the system will automatically detect whether the model can be printed out or 
not. At the same time, in the Neobox system, the design of models, the speed of printing, and the amount of material used are all taken into account. When some parts of a 3D model with large inclination, the system automatically adds the supporting structure. While viewing the print preview, users can click to turn off the automatic addition support. In the Neobox system, there are three types of printing speeds: low, medium, and high. The faster the printing speed, the lower the printing accuracy. Users can choose different printing speeds according to their own needs. The amount of internal filling is proportional to the amount of material used. If users want to save some material, users can choose a low-density filling to print. The internal filling of the model is expressed as a percentage. The greater the percentage, the more material is used. The system default filling amount is $20 \%$. In the interface of Figure 5, users can select different fillings by dragging the icon of the filling amount.

- FDM 3D Printer with Neobox-Q model, the print size is $127 \mathrm{~mm} * 127 \mathrm{~mm} * 130 \mathrm{~mm}$, and the printed material used is Poly Lactic Acid (Abbreviation: PLA), see Figure 6. When a 3D model size boundary is larger than the maximum print boundary value or smaller than the minimum print boundary value, the next print will not be performed. By manual touch, users can reduce the model range to that can be printed out by the printer. The minimum print boundary (Length, width, and height) is $4 \mathrm{~mm} * 2 \mathrm{~mm} * 2 \mathrm{~mm}$. The users can print one or more arbitrary models using the software. After the print is complete, the information about whether the print is successful and the user's print experience is collected as the feedback automatically.

In Figure 6, there are many hardware design details be considered and shown in picture 2 and 3. In order to ensure the safety of the printing process, a flip-top, translucent, vented protective cover is designed, and a separate detachable child lock is provided to prevent accidental opening of the child during printing. It is also stated that children need to be under the supervision of an adult. During model printing test, there are hundreds of 3D models be printed successfully. Eight photos of printed modes are shown form picture 4 to 11 in Figure 6.

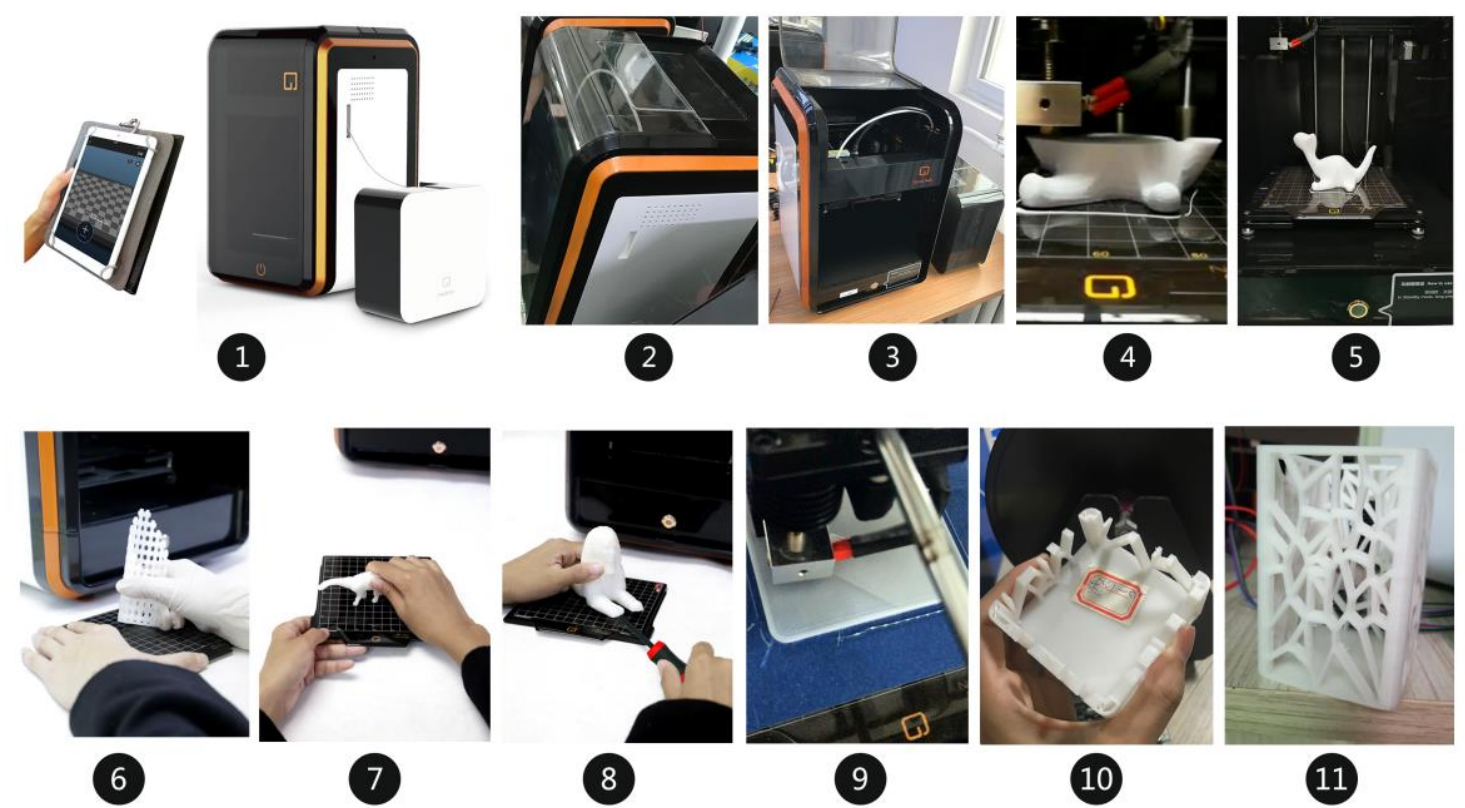

Figure 6. The used 3D printer and tablet computer in the testing

In this paper, a six-point scale is used to measure the user's print experience. The print difficulty is divided into six different levels: hard to complete, hard, bit of hard, easy, very easy, and considerably easy. 22 home users are randomly selected, including 12 women and 10 men, aged between 18 and 50 years old. The results in Figure 7 show that $9.1 \%$ think it is considerably easy, $31.8 \%$ thinks it is very easy to get started, $45.5 \%$ think it is easy, and $13.6 \%$ think it is a bit of hard, no one thinks it is very hard or hard to complete.

Although the users participating in the test are all non-technical home users, everyone completed their print task without prior training. More than $86.4 \%$ of users think the printing process is easy, only $13.6 \%$ think it's a bit hard. Their difficulty lies in the confusion of choosing the right printing material, which is not directly related to the interaction software itself. The testing results demonstrate the 
significance of user preferences for improving product availability. As shown in Figure 1, the testing data can be used to optimize the product in the evaluate phase of the ContinUE model. At this point, the preferences of home users for the two key steps have been integrated into the designed product, and users' needs have become the choice of printing materials, where $13.6 \%$ of users feel a bit of hard. This knowledge can continue to be used to improve the design process of the software to complete the life cycle in Figure 1.

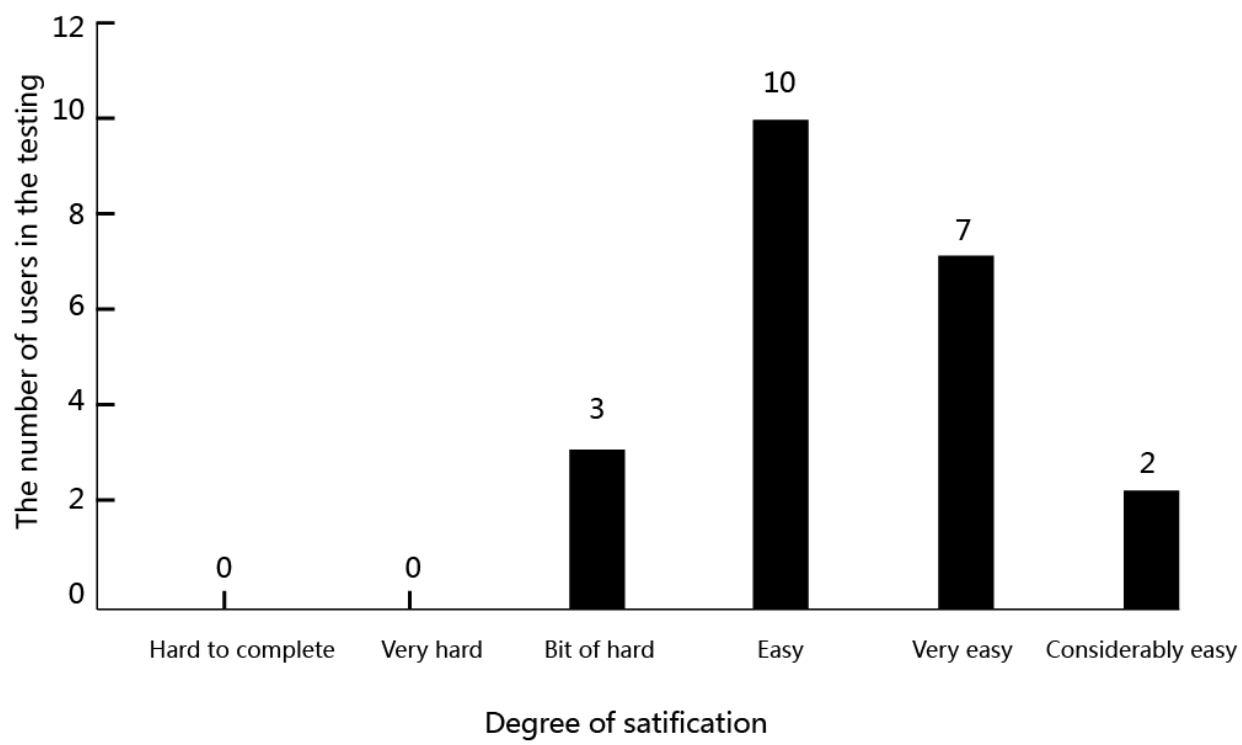

Figure 7. Satisfaction survey

\section{DISCUSSION AND CONCLUSION}

This case study integrates the ContinUE model to the design process of the 3D printing interactive software to capture the knowledge of home users that is related to design purposes. Based on the questionnaire results in Section 3.2 and the testing results in Section 3.3, we can draw the following conclusions:

- The questionnaire results demonstrate the difference between user information and knowledge. The correlation coefficient results show that the home user's gender, age and 3D Printing experience have less impact on their operational preferences. However, this conclusion is not so absolute, for example, for the age of home users, when we design the software for children, age is a user knowledge that must be considered. In this study, only users' preferences in 3D Printing key steps are related to design purposes.

- The preferences of home users for the two key steps are not consistent. Although home users have little or no prior knowledge both creating 3D models and setting 3D Printing parameters, some of them tend to create models themselves, but no one chooses to set parameters all by themselves. This phenomenon may be due to home users' interest habits. Creating a 3D model is more attractive to users than setting parameters, although they are both unknown for users. It is worth noting that, although some people choose to create their own 3D models, they still print successfully.

- The preferences of home users for the two key steps significantly improve the user experience with 3D Printing interactive software, where $100 \%$ of them complete their printing and $86.4 \%$ of them think the printing process is easy. Testing results show that the need of some users changes into the choice of printing material after experiencing the designed product. Based on the results obtained, it would be beneficial for a designer to capture not just the pre-use experience as discussed in Section 3.2, and the post-use experience above.

\section{REFERENCES}

Blackmer, B. E. (2005), "Knowledge on knowledge", Journal of Interior Design, Vol. 31 No. 1, p. viiexii. Boztepe, S. (2007), "Toward a framework of product development for global markets: a user-value-based approach”, Design studies, Vol. 28 No. 5, pp. 513-533. http://dx.doi.org/10.1016/j.destud.2007.02.010 
Camburn, B. A., Auernhammer, J. M., Sng, K. H. E., Mignone, P. J., Arlitt, R. M., Perez, K. B. and Wood, K. L. (2017, August), "Design innovation: A study of integrated practice", In ASME 2017 International Design Engineering Technical Conferences and Computers and Information in Engineering Conference (pp. V007T06A031-V007T06A031). American Society of Mechanical Engineers. http://dx.doi.org/10.1115/DETC2017-68382

Chamorro-Koc M., Popovic V. and Emmison M. (2008), "Using visual representation of concepts to explore users and designers' concepts of everyday products[J]”, Design Studies, Vol. 29 No. 2, pp. 142-159. http://dx.doi.org/10.1016/j.destud.2007.12.005

Cross, N. (2011), 'Design thinking: Understanding how designers think and work", Berg.

Easton, T. A. (2009), "The design economy: a brave new world for businesses and consumers", The Futurist, Vol. 43 No. 1, p. 42.

Gershenfeld, N. (2008)," Fab: the coming revolution on your desktop-from personal computers to personal fabrication", Basic Books.

Groat, L. N. and Wang, D. (2013), Architectural Research Methods. John Wiley \& Sons.

$\mathrm{Hu}$, S. J. (2013), "Evolving paradigms of manufacturing: from mass production to mass customization and personalization", Procedia CIRP, Vol. 7, pp. 3-8.

Huang, X., Kristal, M. M. and Schroeder, R. G. (2008), "Linking learning and effective process implementation to mass customization capability”, Journal of Operations Management, Vol. 26 No. 6, pp. 714-729. http://dx.doi.org/10.1016/j.jom.2007.11.002

Hudson, N., Alcock, C. and Chilana, P. K. (2016, May), "Understanding newcomers to 3D printing: Motivations, workflows, and barriers of casual makers", In Proceedings of the 2016 CHI Conference on Human Factors in Computing Systems (pp. 384-396). ACM. http://dx.doi.org/10.1145/2858036.2858266

Micallef, J. (2015), “Timeline of 3D printing design milestones”, In Beginning Design for 3D Printing (pp. 397401). Apress, Berkeley, CA. http://dx.doi.org/10.1007/978-1-4842-0946-2_14

Mueller S. (2017), “3D printing for human-computer interaction”. interactions (pp. 76-79) http://dx.doi.org/10.1145/3125399

Neagle C. (2013, 31 January 2015), “3D printers: Not for the average consumer”, Available: http://www.networkworld.com/article/2165120/data-center/3d-printers--not-for-the-averageconsumer.html\#more

Pohlmeyer, A. E., Hecht, M. and Blessing, L. (2009), "User Experience Lifecycle Model Continue [Continuous User Experience]. Der Mensch imMittepunkttechnischerSysteme”, Fortschritt-Berichte VDI Reihe, Vol. 22, pp. 314-317.

Sanders, E. B. N. and Stappers, P. J. (2012), Convivial Toolbox: Generative Research for The Front End of Design. Amsterdam: BIS.

Shapeways. (2012, 20 February 2015). Available: http://www.shapeways.com/blog/archives/1344-Have-YourSay-in-a-3D-Printing-Community-Survey.html

Turbovich, Z. N., Avital, I., Mazor, G., Das, A. K. and Kalita, P. C. (2017, January). "Personal 3D Printer: Selfdesign and Manufacturing", In International Conference on Research into Design (pp. 327-338). Springer, Singapore. http://dx.doi.org/10.1007/978-981-10-3518-0_29

Underwood, G. (2014), "RP vs workshop: how modelling methods affect early design development”, In DS 78: Proceedings of the 16th International conference on Engineering and Product Design Education (E and PDE14), Design Education and Human Technology Relations, University of Twente, The Netherlands, 0405.09. 2014 (pp. 537-542).

Von Hippel, E., De Jong, J. P. and Flowers, S. (2012), "Comparing business and household sector innovation in consumer products: findings from a representative study in the United Kingdom", Management Science, Vol. 58 No. 9, pp. 1669-1681. http://dx.doi.org/10.1287/mnsc.1110.1508

Von Hippel, E. (2005), "Democratizing innovation: The evolving phenomenon of user innovation", Journal fürBetriebswirtschaft, Vol. 55 No. 1, pp. 63-78. http://dx.doi.org/10.1007/s11301-004-0002-8

\section{ACKNOWLEDGMENTS}

We are grateful to the software and hardware engineers in this project. We also appreciate all of the contributors who generously spent time answering the questionnaires and participating in the software testing section. 